\title{
Early Versus Late Tracheostomy in Outcome of Patients Admitted in Neurosurgical Intensive Care Unit.
}

\author{
Shiwani Rai ${ }^{1}$, Prasansa Sharma ${ }^{2}$, Sofiya Makajoo $^{2}$, Balgopal Karmacharya ${ }^{2}$, Nikunja Yogi ${ }^{2}$ \\ ${ }^{1}$ Department of ENT, Manipal Teaching Hospital, Pokhara, Nepal \\ ${ }^{2}$ Department of Neurosurgery, Manipal Teaching Hospital, Pokhara, Nepal \\ Correspondence: \\ Dr. Shiwani Rai \\ Assistant Professor. Department of ENT \\ Manipal Teaching Hospital, Pokhara Nepal \\ Email: shiwani.rai@manipal.edu.np
}

\begin{abstract}
Background: Tracheostomy is a commonly performed procedure in neurosurgical Intensive Care Units (ICU) performed to secure airway, aid in pulmonary toileting, and minimize ventilator-associated pneumonia (VAP) in cases requiring prolonged mechanical ventilation. Although early tracheostomy has been advocated rampantly in recent days, its benefit over late tracheostomy and the timing itself has been very controversial. In this study, we tried to study the effect of timing of tracheostomy in the outcome of patients in our ICU. Materials and methods:This is a retrospective study carried out over a period of one and a half years in a tertiary care center in western Nepal. Early tracheostomy was defined as those done within 4 days of endotracheal intubation and late were those done thereafter. Outcomes were studied in terms of length of ICU stay, hospital stay, mechanical ventilation, duration of tracheostomy in situ, VAP and mortality and complication over 90 days. Statistical analysis was done using SPSS 20.0. Results: There were 67 cases included in the study, out of which $27(40.3 \%)$ underwent early and $40(59.7 \%)$ underwent late tracheostomy. The Mean duration of ICU stay, tracheostomy in situ duration, mechanical ventilation duration, and VAP were the parameters showing a significant difference between the two groups. There were $13(19.4 \%)$ cases having complications in our series of which $6(9 \%)$ of cases were from the early tracheostomy group and 7 $(10.4 \%)$ of the cases were from the late tracheostomy group $(\mathrm{p}=0.63)$. Conclusion: Early tracheostomy is beneficial in a neurosurgical patient in terms of a decrease in ICU stay, duration of mechanical ventilation, duration of tracheostomy in situ, and VAP.
\end{abstract}

Key words: Complications, Intensive Care Unit, Neurosurgical patients, Tracheostomy.

$\mathrm{T}$ Tracheostomy is a commonly performed procedure in neurosurgical Intensive Care Units (ICU). The primary indications of tracheostomy in such set up is the protection of the airway in moderate to severe craniofacial injuries, to protect the airway from aspiration injuries seen in many neurological conditions and as an aid in pulmonary toileting and securing airway in cases requiring prolonged mechanical ventilation. There has been no clear consensus in the timing of tracheostomy so far. ${ }^{1-3}$ In deciding for the timing of tracheostomy one has to be very careful that early tracheostomy might lead to unnecessary surgery in some cases whereas late tracheostomy might lead to prolonged endotracheal intubation and its disadvantages leading to potentially prolonged weaning from mechanical ventilation. In this study

21

Date submitted: 09/ 05/2020

Date accepted: 15/05/2020 we tried to see the effect of early tracheostomy in various patient outcomes like hospital and ICU stay; mortality; total tracheostomy and ventilation days; and ventilator-associated pneumonia (VAP) over late tracheostomy.

\section{Methods and Materials:}

A retrospective study was carried out in all cases undergoing tracheostomy in the neurosurgery intensive care unit (ICU) of Manipal Teaching Hospital, Pokhara, Nepal from Jan 2018 to June 2019. Patients were divided into two groups; those who had undergone tracheostomy within 4 days of endotracheal intubations were allotted to the early tracheostomy group (ET) and those who had undergone tracheostomy after 4 days of intubation were allotted in late tracheostomy (LT) group. The

egneuro, Volume 02, Issue 02, 2020 
objective of the study was to evaluate the outcome of patients in terms of hospital stay, ICU stay, duration of mechanical ventilation, mortality, time to removal of tracheostomy tube and ventilator assisted pneumonia (VAP) in between early and late tracheostomy group. There is no definite consensus in literature for a fixed cutoff of timing determining early and late tracheostomy. Our neurosurgical ICU protocol defines early tracheostomy as 4 days from endotracheal intubation which has been followed in this study.

Patient having decreased level of consciousness or risk of aspiration due to various neurological insults requiring prolonged ventilator support, those requiring active pulmonary hygiene care for copious secretions, pulmonary infiltrates, etc. were the commonest reasons for tracheostomy in our ICU. The decision for tracheostomy was taken by the team of treating neurosurgeons and an open tracheotomy was carried out in operation theatre under general anesthesia by neurosurgeons, ENT surgeons, or resident under supervision. Sputum was usually sent at intubation, during tracheostomy and every seven days till the culture was negative. Tracheostomy care was done as per the guidelines by trained ICU nurses. The tracheostomy tube was first changed after the 7th day and every 5 days thereafter. The patient who had been successfully weaned off the ventilator was shifted out of ICU to a high dependency ward as per neurosurgeon's assessment. Patients were followed up for 90 days from admission for any complications or adverse events.

Data of patients undergoing tracheostomy were collected from operative records and ICU charts. Patients of all age groups and both sex were included. Those having incomplete records left against advice without completing the treatment and admitted to the ICU with pre-existing tracheostomy tube received from other wards or hospitals were excluded from the study. Records were retrieved from the Medical records Department (MRD) and data were tabulated and evaluated statistically using IBM SPSS 20.0. Continuous variables were compared using student's t-test and discrete variables were compared using Chi-square or Fischer's exact test and a p-value of 0.05 or less was considered significant.

\section{Results:}

During the study duration, 89 patients had undergone tracheostomy under our care. Out of these 17 patients left against advice without completion of treatment and 5 patients had either incomplete or lost records. Thus, 67 patients who fulfilled our study criteria were included in our study out of which 27 (40.3\%) comprised of the early tracheostomy group and $40 \quad(59.7 \%)$ comprised of the late tracheostomy group.

The mean age of the study population was $43.67 \pm 21.27$ years; that of the early tracheostomy group was $47.26 \pm 19.89$ years and the late tracheostomy group was $41.25 \pm 22.09$ years. There were $47(70.1 \%)$ males and $20(20.9 \%)$ females in the study with M:F ratio of 2.35 . The diagnosis of these patients on admission to ICU is depicted in Figure1.

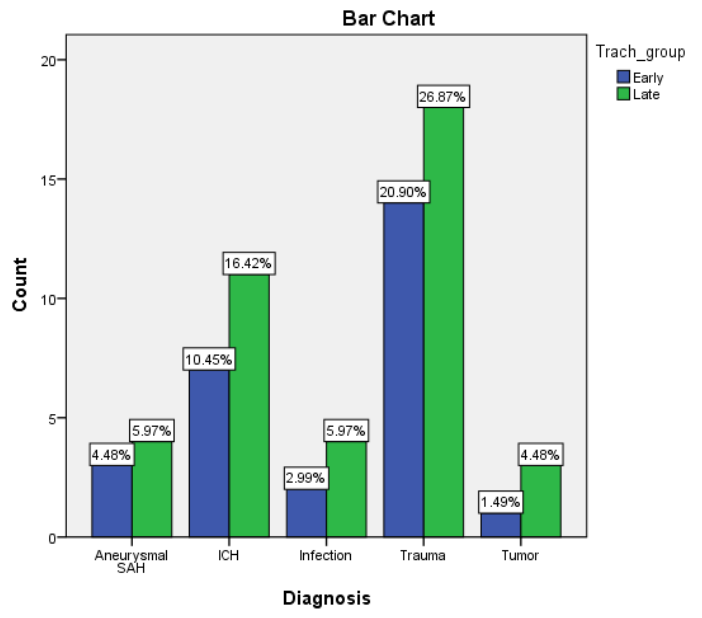

*SAH: Subarachnoid Hemorrhage, ICH: Intracerebral Hemorrhage

Figure 1: Clinical Diagnosis of the patients undergoing tracheostomy

The mean GCS of these patient before tracheostomy was $8.94 \pm 3.23$ and that of early tracheostomy group and late tracheostomy group were $8.74 \pm 3.36$ and $9.08 \pm 3.18$ respectively. The two groups showed no significant difference in terms of age $(\mathrm{p}=0.26)$, sex $(\mathrm{p}=0.56)$, diagnosis $(p=0.98)$ and GCS $(p=0.68)$ suggesting a uniform distribution of the cases in these two groups.

The mean duration of ICU stay of the study population was $17.96 \pm 5.66$ days (9-40 days), the egneuro, Volume 02, Issue 02, 2020 
mean hospital stay was $35.78 \pm 13.04$ days (16-86 days), the mean duration of mechanical ventilation was $14.37 \pm 5.74$ days (6-32 days) and the mean duration of tracheostomy in situ for these patients were $26.93 \pm 9.44$ days (12-60 days). The endpoints of these patients were studied as to their discharge, death, or referral to other rehabilitation centers. The total number of patients discharged after recovery was $46(68.65 \%)$, mortality was seen in $16(23.88 \%)$ cases and $5(7.46 \%)$ patients were referred to other centers on patient request or for rehabilitation. Ventilator-associated pneumonia (VAP) was seen in $49(73.1 \%)$ cases and the organisms grown in them are shown in Figure 2. The commonest organisms seen in our study population were Acinetobacter $(19,28.4 \%)$ and Pseudomonas $(16,23.9 \%)$, and multiple bacterial colonization was seen in $31(46.3 \%)$ cases Fig 2.

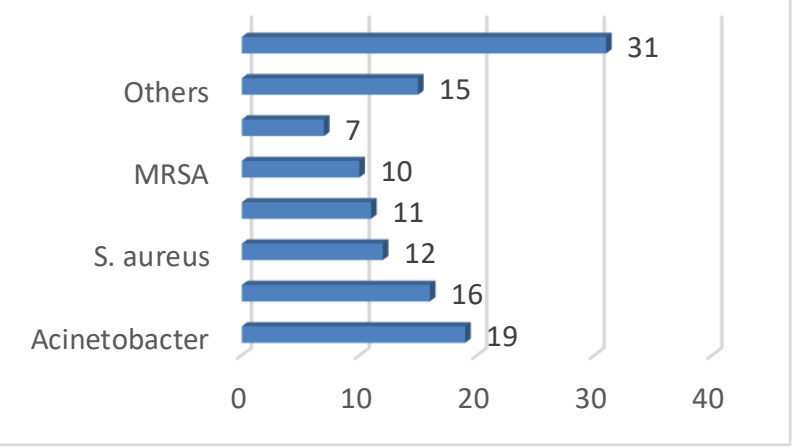

Figure 2: Organisms grown in tracheal aspirate

*S. pneumonia: Streptococcus pneumonia, MRSA: Methicillinresistant staphylococcus aureus, S. aureus: Staphylococcus aureus

The Mean ICU stay, hospital stay, duration of tracheostomy, mechanical ventilation, mortality, and VAP in the two groups, and their difference has been tabulated in Table 1.

The Mean duration of ICU stay, tracheostomy in situ duration, mechanical ventilation duration, and VAP were the parameters showing a significant difference between the two groups. Mortality rate and mean hospital stay though were less in the early tracheostomy group but did not show any significant difference between the two groups.

egneuro, Volume 02, Issue 02, 2020
Table 1: Various outcome measures against early vs Late tracheostomy group

\begin{tabular}{|c|c|c|c|c|}
\hline $\begin{array}{l}\mathbf{S} . \\
\mathbf{N}\end{array}$ & Parameters & $\begin{array}{l}\text { Early } \\
\text { Tracheostom } \\
\text { y }\end{array}$ & $\begin{array}{l}\text { Late } \\
\text { Tracheostom } \\
\text { y }\end{array}$ & $\begin{array}{l}P \text { - } \\
\text { value }\end{array}$ \\
\hline 1 & ICU Stay & $\begin{array}{l}14.63 \pm 3.54 \\
\text { days }\end{array}$ & $\begin{array}{l}20.20 \pm 5.75 \\
\text { days }\end{array}$ & $\begin{array}{l}0.00 \\
*\end{array}$ \\
\hline 2 & Hospital Stay & $\begin{array}{l}31.30 \pm 10.51 \\
\text { days }\end{array}$ & $\begin{array}{l}38.30 \pm 13.81 \\
\text { days }\end{array}$ & 0.20 \\
\hline 3 & $\begin{array}{l}\text { Tracheostom } \\
\text { y in-situ }\end{array}$ & $\begin{array}{l}21.78 \pm 6.90 \\
\text { days }\end{array}$ & $\begin{array}{l}30.40 \pm 9.41 \\
\text { days }\end{array}$ & $\begin{array}{l}0.00 \\
*\end{array}$ \\
\hline 4 & $\begin{array}{l}\text { Mechanical } \\
\text { ventilation } \\
\text { Duration }\end{array}$ & $\begin{array}{l}10.41 \pm 3.50 \\
\text { days }\end{array}$ & $\begin{array}{l}17.05 \pm 5.41 \\
\text { days }\end{array}$ & $\begin{array}{l}0.00 \\
*\end{array}$ \\
\hline 5 & Mortality & $4(5.97 \%)$ & $12(17.91 \%)$ & 0.15 \\
\hline 6 & VAP & $16(23.88 \%)$ & $33(49.25)$ & $\begin{array}{l}0.03 \\
* \\
\end{array}$ \\
\hline
\end{tabular}

There were 13 (19.4\%) cases having complications in our series of which $6(9 \%)$ of cases were from the early tracheostomy group and $7(10.4 \%)$ of the cases were from the late tracheostomy group $(\mathrm{p}=0.63)$. Hemorrhage and accidental decannulation of the tube while performing tracheostomy care were the commonest complications that were managed without any adverse events. Hemorrhage was mainly minor venous ooze which was managed with adrenalinesoaked gauze packing of the wound. None of the patients required re-exposure in the operation theatre. One patient who developed tracheaesophageal fistula did well with conservative management. The details of the complications are tabulated in Table 2.

\section{Table 2: Complications of tracheostomy}

\begin{tabular}{|c|c|c|c|c|}
\hline $\begin{array}{l}\text { S. } \\
\text { N }\end{array}$ & Complications & $\begin{array}{l}\text { Early } \\
\text { Tracheostomy } \\
\mathbf{N}=27\end{array}$ & $\begin{array}{l}\text { Late } \\
\text { Tracheostomy } \\
\mathbf{N}=\mathbf{4 0}\end{array}$ & $\begin{array}{l}\text { Total } \\
N=67\end{array}$ \\
\hline 1 & Hemorrhage & 2 & 3 & $\begin{array}{l}5 \\
(7.5 \%)\end{array}$ \\
\hline 2 & $\begin{array}{l}\text { SurgicalSite } \\
\text { Infection }\end{array}$ & 1 & 1 & $\begin{array}{l}2 \\
(2.9 \%)\end{array}$ \\
\hline 3 & $\begin{array}{l}\text { Accidental } \\
\text { Decanulation }\end{array}$ & 3 & 2 & $\begin{array}{l}5 \\
(7.5 \%)\end{array}$ \\
\hline 4 & $\begin{array}{l}\text { Tracheoesophageal } \\
\text { fistula }\end{array}$ & 0 & 1 & $\begin{array}{l}1 \\
(1.5 \%)\end{array}$ \\
\hline
\end{tabular}

\section{Discussion:}

With the advancements in technologies of critical care, the survival of critical patients has increased and thus has the patients remaining dependent on a mechanical ventilator for a prolonged period. Endotracheal (ET) intubation for a prolonged 
period has its disadvantages of VAP due to bypassing and disabling the laryngeal protective mechanisms, increasing the chances of oropharyngeal contamination of the pulmonary system as well as having a higher chance of damage to the laryngeal and tracheal systems. Tracheostomy has been an effective substitute for prolonged ET intubation as it provides the benefit of easier handling of patients, easier pulmonary toileting, greater patient comfort, reduced need of sedation, the possibility of oral feeding, improved respiratory mechanics, reduced trauma to the oral cavity and lesser chances of VAP. ${ }^{4-6}$

Although the role of tracheostomy has been established in critical care in substitution to prolonged ET intubation, the timing of tracheostomy has been a topic of controversy in recent days. A consensus conference in 1989 suggested that tracheostomy is preferable when ventilator support is expected to exceed 21 days. $^{2}$ However, the statement is controversial and depends upon the opinion of the treating specialist. In the past few years, various studies have defined their cutoff for early and late tracheostomy. Literature search shows early tracheostomy defined as within 2-10 days of mechanical ventilation and late tracheostomy variously defined as any time outside early period within 7-28 days. ${ }^{7-13}$

With all these controversies, a question that stands to date is whether early tracheostomy imparts any benefit in the outcome of patients over late tracheostomy? Various small observational and cohort studies have shown variable outcome differences based on the timing of tracheostomy. ${ }^{10,14-17}$ The difference seen was either beneficial or of no difference however none of the studies showed any detrimental effect of one over another. A Cochrane meta-analysis published in 2012 found no mortality difference between early (2-10days) and late (>10days) tracheostomy group. However, one of the four studies in the meta-analysis found that there was a decrease in ventilator time for early tracheostomy group. ${ }^{18}$ Two recent European randomized trials (Italian multicenter trails and TracMan UK multicenter trial) suggest earlier tracheostomy was not associated with improved survival and that clinicians cannot accurately predict which patient will require prolonged mechanical ventilation. ${ }^{19,20}$
One way to explain these adverse outcomes of early tracheostomy could be the inclusion of patients with different diagnoses in such trails. The advantages of tracheostomy is not similar in various condition and indications of tracheostomy in various conditions like chronic obstructive pulmonary disease (COPD) are different than in neurological and neurosurgical conditions. This has not only been noticed in widespread clinical practice but also on studies of the timing of tracheostomy in various neurological conditions and craniocerebral trauma however larger randomized trials are yet to validate the findings. ${ }^{21-}$

${ }^{24}$ Our study also suggested a significant benefit of early tracheostomy in terms of length of ICU stay, mechanical ventilation, tracheostomy in situ duration, and VAP. There was no significant benefit on the survival of the patients over 90 days and length of hospital stay in the two groups.

Retrospective nature and small sample sizes were the main limitations of our study. Due to the retrospective design, the patients could not be randomized into early and late groups leading into selection bias although we tried to limit this by checking the homogeneity in between two groups in terms of demographics and neurological status (GCS score). A proper randomized study involving multiple centers to include a larger sample size may be a better option to answer and validate most of the findings of this study in the future.

\section{Conclusion:}

Early tracheostomy is beneficial in a neurosurgical patient in terms of a decrease in ICU stay, duration of mechanical ventilation, duration of tracheostomy in situ, and VAP. However, it does not impart any benefit over late tracheostomy in terms of mortality, complications of tracheostomy, and length of hospital stay.

\section{References:}

1. Heffner J E. Timing tracheostomy: calendar watching or individualization of care? Chest 1988;114:361-363.

2. Marsh HM, Gillespie DJ, Baumgartner AE. Timing of tracheostomy in the critically ill patient. Chest 1989;96:190-192.

3. Plummer AL, Gracey DR. Consensus conference on artificial airways in patients receiving mechanical ventilation. Chest 1989;96:178-180.

egneuro, Volume 02, Issue 02, 2020 
4. Boles JM, Bion J, Connors A, Herridge M, Marsh B, Melot $\mathrm{C}$, et al. Weaning from mechanical ventilation. Eur Respir J 2007;29(5):1033-1056.

5. Rodriguez JL, Steinberg SM, Luchetti FA, Gibbons KJ, Taheri PA, Flint LM. Early tracheostomy for primary airway management in the surgical critical care setting. Surgery 1990;108(4):655-659.

6. Lesnik I, Rappaport W, Fulginiti J, Witzke D. The role of early tracheostomy in blunt, multiple organ trauma. Am Surg 1992;58(6):346-9.

7. Griffiths J, Barber VS, Morgan L, Young JD. Systematic review and meta-analysis of studies of the timing of tracheostomy in adult patients undergoing artificial ventilation. BMJ 2005 May 28;330(7502):1243

8. Jeon YT, Hwang JW, Lim YJ, Lee SY, Woo KI, Park HP. Effect of tracheostomy timing on clinical outcome in neurosurgical patients: early versus late tracheostomy. J Neurosurg Aanesthesiol 2014;26(1):22-26.

9. Mehta AB, Cooke CR, Wiener R. Walkey AJ. Hospital Variation in Early Tracheostomy in the United States: a Population-Based Study. Crit Care Med 2016;44:1506151

10. Moller MG, Slaikeu JD, Bonelli P, Davis AT, Hoogeboom JE, Bonnell BW. Early tracheostomy versus late tracheostomy in the surgical intensive care unit. Am J Surg 2005;189(3):293-296.

11. Rumbak MJ, Newton M, Truncale T, Schwartz SW, Adams JW, Hazard PB. A prospective, randomized, study comparing early percutaneous dilational tracheotomy to prolonged translaryngeal intubation (delayed tracheotomy) in critically ill medical patients. Crit Care Med 2004 Aug; 32 (8):1689-1694.

12. Wang HK, Lu K, Liliang PC, Wang KW, Chen HJ, Chen $\mathrm{TB}$, et al. The impact of tracheostomy timing in patients with severe head injury: an observational cohort study. Injury 2012;43(9):1432-1436.

13. Cheung NH, Napolitano LM. Tracheostomy: Epidemiology, Indications, Timing, Technique, and Outcomes. Respiratory care 2014;59(6):895-915.

14. Arabi YM, Alhashemi JA, Tamim HM, Esteban A, Haddad SH, Dawood A, et al. The impact of time to tracheostomy on mechanical ventilation duration, length of stay, and mortality in intensive care unit patients. J Crit Care 2009;24(3):435-440.

15. Olton S, Hariharan S, Chen D. Outcome evaluation of patients requiring tracheostomy in an intensive care unit in Trinidad. West Indian Med J 2009;58(2):173-178.

16. Zheng Y, Sui F, Chen XK, Zhang GC, Wang XW, Zhao S, et al. Early versus late percutaneous dilational tracheostomy in critically ill patients anticipated requiring prolonged mechanical ventilation. Chin Med J 2012;125(11):1925-1930.

17. Scales DC, Thiruchelvam D, Kiss A, Redelmeier DA. The effect of tracheostomy timing during critical illness on long-term survival. Crit Care Med 2008;36(9):2547-2557.

18. Gomes Silva BN, Andriolo RB, Saconato H, Atallah AN, Valente O. Early versus late tracheostomy for critically ill patients. Cochrane Database Syst Rev 2012;3:CD007271

19. Terragni PP, Antonelli M, Fumagalli R, Faggiano C, Berardino M, Pallavicini FB, et al. Early vs late tracheotomy for prevention of pneumonia in mechanically ventilated adult ICU patients: a randomized controlled trial. JAMA 2010;303(15):1483-1489.

20. Young D, Harrison DA, Cuthbertson BH, Rowan K, TracMan Collaborators. Effect of early vs late tracheostomy placement on survival in patients receiving mechanical ventilation: the TracMan randomized trial. JAMA 2013;309(20):2121-2129.

21. Ahmed N, Kuo YH. Early versus late tracheostomy in patients with severe traumatic head injury. Surg Infect 2007;8(3):343-347.

22. Rizk EB, Patel AS, Stetter CM, Chinchilli VM, Cockroft KM. Impact of tracheostomy timing on outcome after severe head injury. Neurocrit Care 2011;15(3):481-489.

23. Shrestha P, Lohani S, Shrestha S, Devkota UP. Outcome Difference in Neurosurgical Patients Based on Timing of Tracheostomy and Ventilator Associated Pneumonia. Nepal Journal of Neuroscience 2018;15(1):19-22.

24. Neupane B, Lamichhane A. Outcome of Early versus Late Tracheostomy in Neurosurgical critical Patient. Nepal Journal of Neuroscience 2019;16(2):38-42. 